preferences as possible. Notions like the sanctity or dignity of human (or other) life fall away. Anything less than utilitarian calculation of "quality life saved' must be superstition, culminating (for example) in Peter Singer's willingness to encourage abortion of, or experimentation on, those whose lives would be less worth living (treating 'potential people' very much as more traditional moralists have thought it right to treat non-human animals).

Hansson gives details of several medical or quasi-medical procedures about which questions can be raised (abortion, the use of fetal tissue, alleviation of infertility, embryo research, gene therapy, eugenics and transgenic experimentation). $\mathrm{He}$ carefully distinguishes (as others have not always done) the questions that can be asked in addition to straightforwardly consequentialist ones. After a brief and critical exposition of Singer's (and Hare's) utilitarianism, he chooses to develop a Kantian approach, drawing on a wider range of Kant's writing than is usual, and developing the argument (as he admits) in ways that Kant himself could not really have admitted. Unlike Kant, for example, he is sure that we do have duties toward non-human animals rather than only towards humanity. $\mathrm{He}$ draws on Carol Gilligan's work to suggest that Justice and Care are both important in Kantian perspective. Although human beings have a special dignity, duties of beneficence toward animals (as intrinsically valuable) are actually more extensive, he suggests, than Singer's defeasible duty not to cause them pain. 'An eagle might not feel pain if we were to expose it to chemical waste like mercury but it is highly detrimental to its ability to live according to its purposiveness' (p 149). It is possible that Hansson could have profited from reading Rollin or Regan on this sort of point.

Finally, he formulates five, quite lengthy, maxims that may help us to cope with the sort of biomedical issues he has previously described. Crucial terms in these maxims include: what is essential for a human being's physical, psychical and moral existence; care; integrity; 'physical, psychical and social well-being'; and 'stewardship of values in a purposive whole'. This last term reflects Hansson's concern for ecological values and for the intrinsically valuable beauty of those wholes. Human beings are superior to others in that they alone can take responsibility, but their duties are to a purposiveness which may conflict with their own sensible interests. In brief, he concludes that a suitably expanded Kantian ethics does provide a theoretical basis for a less consequentialist approach, respecting the autonomy and integrity of individual persons (including potential persons, which are more than merely things that might possibly end up as persons), and affording more protection to non-human animals than Singer's own, animal liberationist principles. The whole is a distinguished, and unusual, contribution to biomedical ethics and Kantian scholarship.

STEPHEN R L CLARK, Department of Philosophy, Liverpool University.

\section{Applied philosophy, morals and metaphysics in contemporary debate}

Edited by Brenda Almond and Donald Hill, 334 pages, London, 1991, Routledge, £10.99

This anthology comprises twenty-eight articles divided among the following topics: The environment; Personal relationships; Terrorism, war and confict; Justice and equality; and Ethics and medicine. The articles were all originally published in the fournal of Applied Philosophy, from whose editorial staff come the co-editors of this anthology. The purpose of this anthology is not at all clear. Two of the most important functions of anthologies are: first, to assemble important papers on a subject or by an individual that were previously unpublished or widely scattered and second, to assemble articles useful for teaching. Since the articles were all published in the same journal, the anthology does not fulfil the first function. Nor is it entirely apt for the second function: seminal articles from other journals that should be required reading are omitted. What the anthology really seems to be is a 'Best of ...' collection for promoting applied philosophy in general and the fournal of Applied Philosophy in particular.
Because of limitations of space, I shall confine the rest of my discussion to the section on ethics and medicine. In general, while the seven articles in this section are competent, none sparkles. Four of the articles concern either the beginning or end of life. E Page argues that gametes should be transferable while embryos should not: transferring embryos would violate the principle that children should not be transferred, while transferring gametes would not. He takes it to be a consequence of this that women who have agreed to be surrogates prior to conception should be held to the agreement. J Trusted bases a compelling criticism of this conclusion on the fact that surrogacy involves more than the incubation of an embryo. A Holland criticises the view that for the first two weeks after conception a fertilised egg is not an embryo and, therefore, not human. This view rests on the observation that for about two weeks the material making up the embryo is not distinct from the material making up the placenta and fetal membranes and it is still possible for the material to develop into two distinct embryos (identical twins). In one of the most interesting articles, A Browne discusses the vagueness of the notion of death and argues that there is no utility in formulating a general stipulative definition of death. Instead he suggests that we would be better off formulating different criteria of death for different purposes.

The remaining three papers in this section deal with a variety of topics. A description of the philosophical issues involved in practical decision-making in a clinical setting is given by D Moros, R Rhodes, B Baumrin and J Strain. $S$ Marshall argues that the right to privacy is neither reducible to other rights nor justified on utilitarian grounds, but is founded on the requirement that a person's autonomy be respected. $\mathbf{R}$ Chadwick rejects the view that a prohibition against selling body parts can be justified on the Kantian ground that persons have duties to themselves, but argues that it can be justified by appeal to a general obligation to promote human flourishing.

ROBERT L FRAZIER, Visiting Assistant Professor of Philosophy, Virginia Commonwealth University, USA. 